\title{
Ischemic Stroke Injury Is Mediated by Aberrant Cdk5
}

\author{
Douglas A. Meyer, ${ }^{1}$ Melissa I. Torres-Altoro, ${ }^{1}$ Zhenjun Tan, ${ }^{3}$ Alessandro Tozzi,,${ }^{5,6}$ Massimiliano Di Filippo,, 5 \\ Vincent DiNapoli, ${ }^{3}$ Florian Plattner, ${ }^{1}$ Janice W. Kansy, ${ }^{1}$ Stanley A. Benkovic, ${ }^{4}$ Jason D. Huber, ${ }^{7}$ Diane B. Miller, ${ }^{4}$ \\ Paul Greengard, ${ }^{8}$ Paolo Calabresi, ${ }^{5,6}$ Charles L. Rosen, ${ }^{3}$ and James A. Bibb ${ }^{1,2}$ \\ ${ }^{1}$ Department of Psychiatry, ${ }^{2}$ Department of Neurology and Neurotherapeutics, The University of Texas Southwestern Medical Center, Dallas, Texas 75390 , \\ ${ }^{3}$ Department of Neurosurgery, West Virginia University School of Medicine, Morgantown, West Virginia 26506-9183, ${ }^{4}$ National Institute for Occupational \\ Safety and Health, Centers for Disease Control and Prevention, Morgantown, West Virginia 26505, ${ }^{5}$ Clinica Neurologica, Università di Perugia, Ospedale S. \\ Maria della Misericordia, 06156 Perugia, Italy, ${ }^{6}$ Fondazione Santa Lucia-Istituto di Ricovero e Cura a Carattere Scientifico, 00184 Rome, Italy, ${ }^{7}$ Department \\ of Basic Pharmaceutical Sciences, West Virginia University School of Medicine, Morgantown, West Virginia 26506-9530, ${ }^{8}$ Laboratory of Molecular and \\ Cellular Neuroscience, The Rockefeller University, New York, New York 10021
}

Ischemic stroke is one of the leading causes of morbidity and mortality. Treatment options are limited and only a minority of patients receive acute interventions. Understanding the mechanisms that mediate neuronal injury and death may identify targets for neuroprotective treatments. Here we show that the aberrant activity of the protein kinase Cdk5 is a principal cause of neuronal death in rodents during stroke. Ischemia induced either by embolic middle cerebral artery occlusion (MCA0) in vivo or by oxygen and glucose deprivation in brain slices caused calpain-dependent conversion of the Cdk5-activating cofactor p35 to p25. Inhibition of aberrant Cdk5 during ischemia protected dopamine neurotransmission, maintained field potentials, and blocked excitotoxicity. Furthermore, pharmacological inhibition or conditional knock-out (CKO) of Cdk5 prevented neuronal death in response to ischemia. Moreover, Cdk5 CKO dramatically reduced infarctions following MCAO. Thus, targeting aberrant Cdk5 activity may serve as an effective treatment for stroke.

Key words: biomarker; calpain; Cdk5; ischemia; neuroprotection; stroke

\section{Introduction}

Stroke is the third leading cause of death in the United States and represents a substantial social and economic burden worldwide, as those who survive ischemic injury can develop neurological deficits that may result in permanent disabilities. Ischemic stroke results from a thromboembolic event causing decreased cerebral perfusion. While advances have been made regarding the cellular and molecular basis of ischemic injury, it has proven difficult to translate this knowledge into treatments that improve recovery. Thrombolytic therapies, such as tissue plasminogen activator (tPA) administration, are currently the only effective treatment available. Although these treatments reduce stroke damage and improve outcomes, patients are often left disabled. Furthermore, the majority of patients are not candidates for mechanical or pharmacologic thrombolysis. It is

Received Oct. 10, 2013; revised April 16, 2014; accepted April 18, 2014.

Author contributions: D.B.M., P.C., C.L.R., and J.A.B. designed research; D.A.M., M.I.T.-A., Z.T., A.T., M.D.F., V.D., J.W.K., S.A.B., and J.A.B. performed research;J.A.B. contributed unpublished reagents/analytic tools; D.A.M., M.I.T.-A.,Z.T., A.T., M.D.F., P.C., C.L.R., and J.A.B. analyzed data; M.I.T.-A., F.P., J.D.H., D.B.M.,P.G., P.C., C.L.R., and J.A.B. wrote the paper.

This work was supported by the European Community contract number 222918 (REPLACES) FP7—Thematic priority HEALTH to P.C., and U.S. National Institutes of Health grants to P.G. (MH090963 and DA10044), J.D.H. (NS061954), and J.A.B. (MH79710, MH083711, DA016672, DA033485, NS073855). This work was also supported by DA0018343 Pilot Project funding (J.A.B.). We thank W. Lai, X. Li, and M. Kouser, for technical assistance, and F. Gillardon and Boehringer Ingelheim, for indolinone. We thank P. Chambon and Universaire de Srasbourg, for Prp$E R^{\top}$ transgenic mice, and A. Sonneborn, for help with manuscript preparation.

The authors declare no competing financial interests.

Correspondence should be addressed to James A. Bibb, PhD, at the above address. E-mail: james.bibb@utsouthwestern.edu.

DOI:10.1523/JNEUROSCI.4368-13.2014

Copyright $\odot 2014$ the authors $\quad 0270-6474 / 14 / 338259-09 \$ 15.00 / 0$ therefore critical to identify the biochemical mechanisms underlying stroke-related damage so that treatments may be developed to help improve recovery.

Ischemia triggers a series of pathological events in the brain, leading to neuronal loss by apoptosis and other mechanisms of cellular injury. Severe ischemia causes neurons to undergo irreversible membrane depolarization and immediate cell swelling (Centonze et al., 2001; Larsen et al., 2006), while mild ischemia induces slow excitotoxicity and neurodegeneration (Hagemann et al., 1998). These two processes account for both the early neuronal loss observed in the ischemic core and the delayed damage in the surrounding penumbra (Calabresi et al., 2003; Lo et al., 2003). At the cellular level, the ion exchange balance across the cell membrane is lost, disrupting normal cellular processes like oxidative phosphorylation required for respiration, resulting in depolarization of the cell membrane. Excitotoxic glutamatergic neurotransmission ensues, triggering the activation of proteases, phosphatases, phospholipases, and free radical actions (Lipton, 1999).

Excitotoxic glutamate released during ischemia may activate NMDA receptors, resulting in $\mathrm{Ca}^{2+}$ overload. Consequently, $\mathrm{Ca}^{2+}$ activation of the cysteine protease calpain contributes to ischemic damage (Wells and Bihovsky, 1998; Lipton, 1999). A key calpain substrate is p35, the activating cofactor of Cdk5. Under physiological conditions, $\mathrm{Cdk} 5 / \mathrm{p} 35$ is involved in many neuronal processes, including dopaminergic neurotransmission (Cheung $\mathrm{ZH}$ et al., 2006). However, calpain-dependent conversion of Cdk5/p35 to Cdk5/p25 (Fig. 1A) is neurotoxic and has been implicated in various neurodegenerative diseases, including 
Alzheimer's (Monaco, 2004) and Parkinson's (Alvira et al., 2006; Smith et al., 2006). Here we examine the role of Cdk5/ p25 in ischemic injury. We implicate Cdk5 in stroke pathology using a number of in vivo and ex vivo paradigms and demonstrate that aberrant Cdk5 activity is an important target for treatment and prevention of ischemic damage.

\section{Materials and Methods}

Animals. Adult (2-3 months) male Cdk5 conditional knock-out (CKO) mice were generated and maintained as previously described (Hawasli et al., 2007). In brief, floxed Cdk5 and Cre-ER $^{\mathrm{T}}$ mice (Weber et al., 2001) were crossed and male offspring at 8 weeks of age injected with 4-hydroxytamoxifen for $15 \mathrm{~d}$ $(66.7 \mathrm{mg} / \mathrm{kg}$, i.p.). All experiments were performed 2-4 weeks after injections, when the males were 12-14 weeks old. Mice were housed four or five per cage in a colony maintained at $23^{\circ} \mathrm{C}$ with a $12 \mathrm{~h}$ light/dark cycle and ad libitum food and water. Aged (9-12 months) female Sprague Dawley rats were housed in the West Virginia University animal facilities until 18 months of age under standard $12 \mathrm{~h}$ light/dark cycle and ad libitum food and water. Rats were confirmed past estrus via immunoassay of blood samples using a rat estrogen ELISA. Only rats exhibiting discontinuation or disruption in the normal estrus cycle by 18 months were used to assure reproductive senescence (Alkayed et al., 2000).

Procedures were performed during the light cycle as approved by the University of Texas Southwestern Institutional Animal Care and Use Committee and conducted in accordance with the applicable portions of the National Institutes of Health (NIH) Guide for the Care and Use of Laboratory Animals. Some protocols have been approved by the West Virginia University Animal Care and Use Committee and abide by NIH guidelines. Some experiments were conducted under the approval of the Istituto Superiore Sanità (Italy) and in accordance with European Communities Council Directive of November 1986 (86/609/ECC).

Embolic middle cerebral artery occlusion. Middle cerebral artery occlusion (MCAO) was performed as described previously (Zhang et al., 1997; Dinapoli et al., 2006). Briefly, rats or mice were anesthetized (isoflurane, $4 \%$ induction; $1 \%$ maintenance). A modified PE-50 microcatheter was inserted into the right external carotid artery stump and advanced into the MCA. Placement in the proximal MCA was verified by a sudden decrease in cerebral blood flow using a laser Doppler probe. The microcatheter was withdrawn $1 \mathrm{~mm}$, allowing cerebral blood flow to return to baseline, and then a prepared fibrin clot was injected. Successful MCAO was confirmed by continuous monitoring of cerebral blood flow. The external carotid artery stump was ligated, the common carotid artery made patent, and the neck incision closed. For tPA administration, stroke was allowed to persist for $2 \mathrm{~h}$, at which time tPA $(5 \mathrm{mg} / \mathrm{kg})$ was administered via the femoral vein over $30 \mathrm{~min}$ with an initial $30 \%$ bolus. After recanalization was noted by increased cerebral blood flow ( $\sim 80 \%$ of baseline), the scalp and femoral incision were closed and the animal awakened from anesthesia. For purposes of comparison, the study of infarct volume and biochemistry were repeated using unilateral procedures. versus control; Student's t test. p35

calpain cleavage site

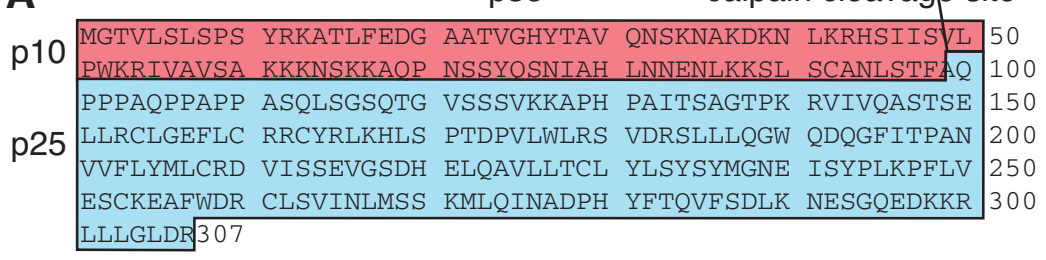

B
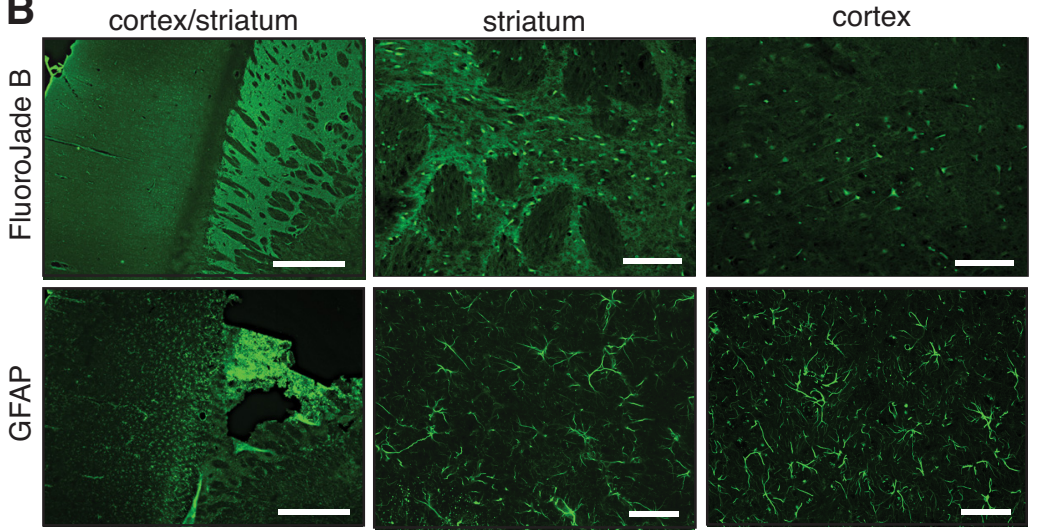

C post-stroke period (h)
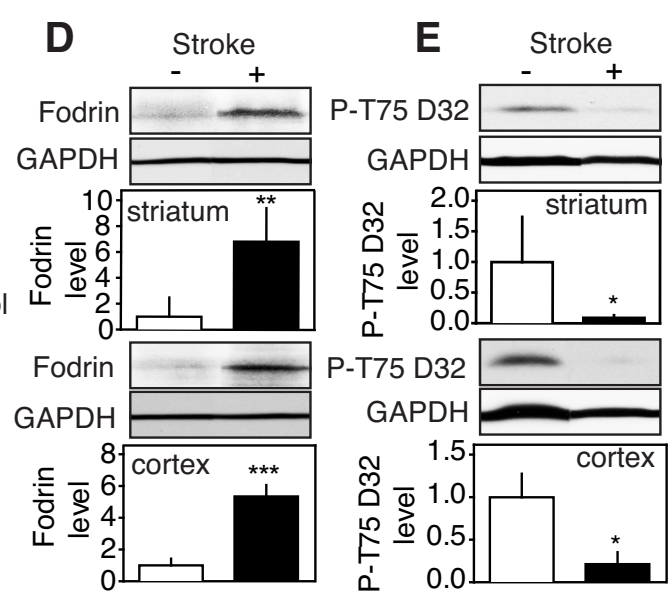

Figure 1. Stroke induces dysregulation of Cdk5. A, p35/p25 aa sequence. B, Staining of stroked brain hemispheres $6 \mathrm{~h}$ after reperfusion for FJB and $24 \mathrm{~h}$ after reperfusion for GFAP. Scale bars: left, $2 \mathrm{~mm}$; center, right, $100 \mu \mathrm{m}$. C, Quantitative $48 \mathrm{~h}$ after unilateral MCAO. D, E, Quantitative immunoblots of cleaved fodrin $(\boldsymbol{D})$ and phospho-Thr75 DARPP-32 (E) from ysates of striatum and prefrontal cortex of control and stroked brain hemispheres at $6 \mathrm{~h}$ after unilateral MCA0. Aged $(9-12$ months) rats were used for studies in $\boldsymbol{B}-\boldsymbol{E}$. Data represent means \pm SEM; $n=6-8 ;{ }^{*} p<0.05,{ }^{* *} p<0.01,{ }^{* * *} p<0.005$,

Slice pharmacology and oxygen and glucose deprivation. Acutely prepared coronal slices and or oxygen and glucose deprivation (OGD) treatment for ex vivo studies were conducted as described previously (Nishi et al., 1997; Sahin et al., 2007, 2008). Briefly, WT and Cdk5 CKO mouse brains were placed in ice-cold oxygenated Kreb's bicarbonate buffer bubbled with $95 \% \mathrm{O}_{2}$ and $5 \% \mathrm{CO}_{2}$. Coronal slices $(350 \mu \mathrm{m})$ were made and striatal or cortical slices ( $2 \mathrm{~mm}$ from bregma) were microdissected and incubated at $30^{\circ} \mathrm{C}$. For OGD, slices were equilibrated in Kreb's buffer for $30 \mathrm{~min}$, as before, followed by exchange with buffer in which glucose has been replaced by $10 \mathrm{~mm}$ sucrose and bubbled with $100 \% \mathrm{~N}_{2}$. For slice treatments with the Cdk5 inhibitor indolinone A (Indo A), incubation periods were $1 \mathrm{~h}$ at the concentrations indicated. Calpeptin and calpain inhibitor 3 treatments were with $20 \mu \mathrm{M}$ for $1 \mathrm{~h}$. SFK81297 treatment was at $1 \mu \mathrm{M}$ for $5 \mathrm{~min}$. Control untreated slices were incubated for equal amounts of time, and treated with vehicle-containing buffer. Following these treatments, slices were snap frozen in dry ice and stored at $-80^{\circ} \mathrm{C}$ until processed for quantitative immunoblot analysis. 

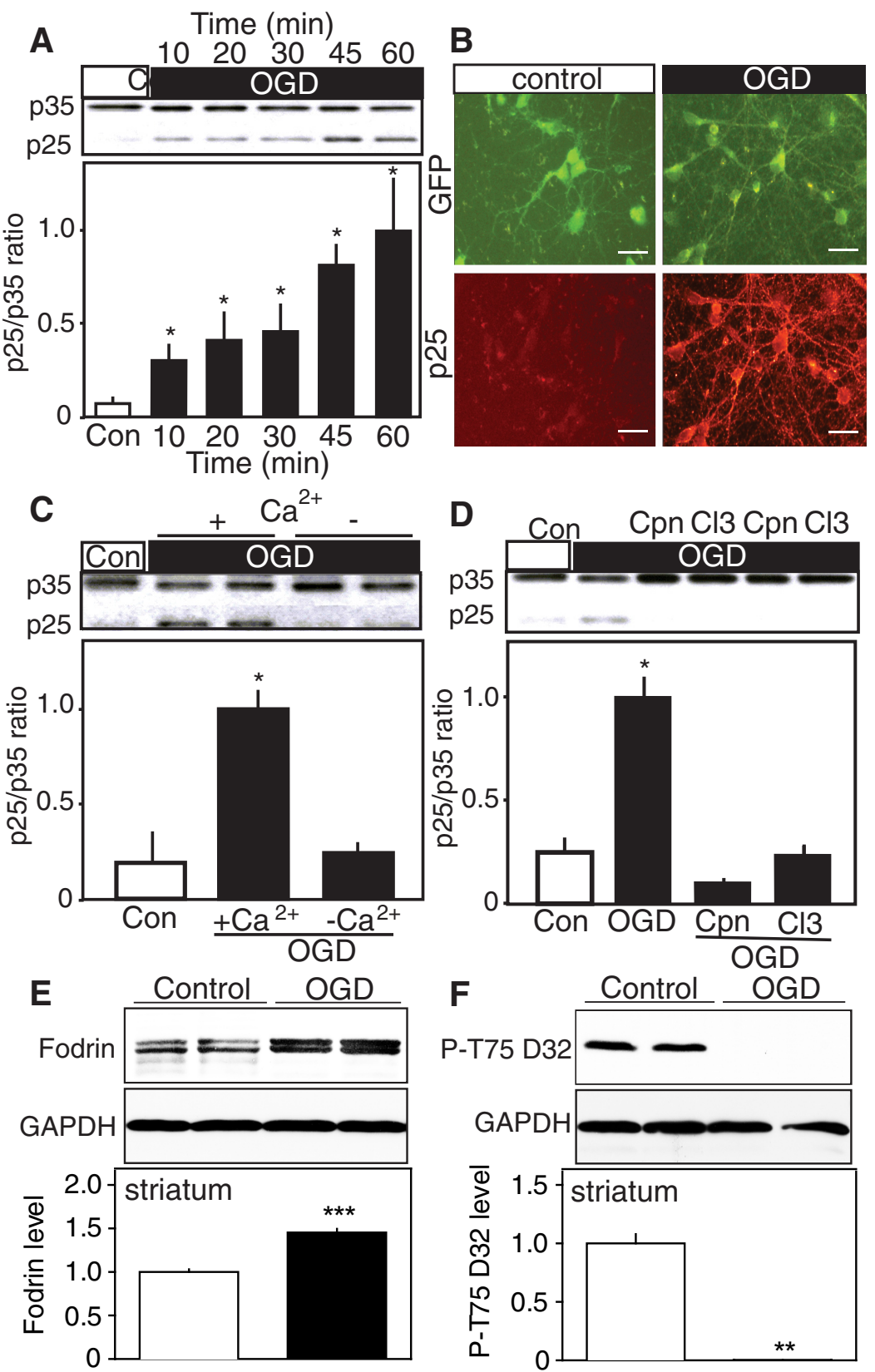

$\mathbf{F}$

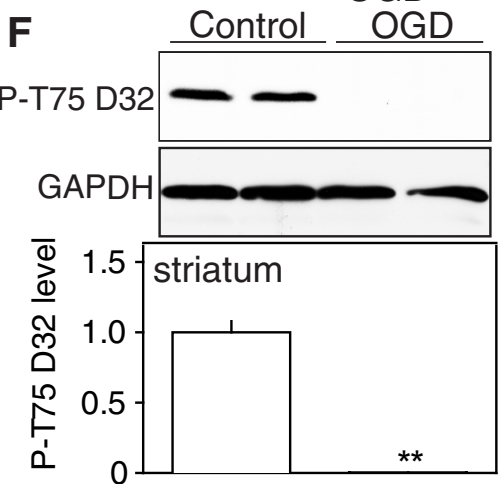

Figure 2. Ischemic Cdk5 dysregulation in acute brain slices is dependent upon calpain. $\boldsymbol{A}$, Time-dependent p25 generation in striatal slices in response to OGD. Quantitative immunoblotting of lysates from slices subjected to $0 G D$ for the indicated period is shown. Controls (Con) were incubated in oxygenated buffer for $60 \mathrm{~min}$. B, GFP and p25 detection in costained GFP-expression vector-transfected primary cultured striatal neurons before and after OGD. Scale bars, $25 \mu \mathrm{m}$. C, Attenuation of OGD-induced p25 generation by $\mathrm{Ca}^{2+}$ removal. $\boldsymbol{D}$, Inhibition of OGD-dependent 25 generation by calpain inhibitors calpeptin or calpain inhibitor 3 . $\boldsymbol{E}, \boldsymbol{F}$, Quantitative immunoblots of cleaved fodrin $(\boldsymbol{E})$ and phospho-Thr75 DARPP-32 $(\boldsymbol{F})$ in lysates from acutely prepared mouse striatal slices left untreated (Control) or exposed to OGD (20 min). Data represent means \pm SEM; $n=4-6 ;{ }^{*} p<0.05,{ }^{* *} p<$ $0.01,{ }^{* * *} p<0.005$; Student's $t$ test versus control.

Histological procedures and immunoblotting. Immunoblotting was performed as described previously (Sahin et al., 2004). Briefly, tissue homogenates were prepared from rats and control versus Cdk5 CKO mice that had undergone MCAO and reperfusion. Equal amounts of total protein were resolved by SDS-PAGE and transferred to nitrocellulose membranes. Membranes were probed with primary antibodies, washed, and incubated with HRP-conjugated secondary antibodies and detected using ECL chemiluminescence (GE Healthcare). Membranes were exposed to $\mathrm{x}$-ray film and resulting autoradiograms were scanned and analyzed using NIH ImageJ. Quantitation is presented as the normalized ratio of phosphorylated protein to total protein or loading control. Anti- p35 (C-19) was from Santa Cruz Biotechnology. Anti-phospho-Ser-845 GluR1 was from PhosphoSolutions. Anti-fodrin was from Enzo Life Sciences. Anti-GFAP was from DAKO. Anti-DARPP-32 and anti-phospho-Thr-75 DARPP-32 have been previously described (Bibb et al., 1999).

All immunohistochemistry was performed essentially as described previously (Bibb et al., 2000). Briefly, rats that had undergone unilateral MCAO were transcardially perfused with $4 \%$ formaldehyde, cryoprotected overnight in $25 \%$ sucrose, cyrosectioned $(7 \mu \mathrm{m})$, and mounted onto slides for staining. Primary antibody incubations were overnight. Slides were washed with PBS and incubated with secondary antibodies before dehydration and coverslipping in DPX. Images were captured and analyzed using a laser scanning confocal microscope.

For Fluoro-Jade B (FJB) staining, slides were immersed in distilled water for $1 \mathrm{~min}$, in $70 \%$ ethanol for $2 \mathrm{~min}$, and then in distilled water for $2 \mathrm{~min}$. They were transferred to the staining solution for $20 \mathrm{~min}$ (stock FJB solution, $10 \mathrm{mg}$ of dye in $100 \mathrm{ml}$ of distilled water; $0.005 \%$ working solution: $4 \mathrm{ml}$ of stock solution in 96 $\mathrm{ml}$ of $0.1 \%$ acetic acid). Following washing $(3 \times)$ for $1 \mathrm{~min}$ each in water, they were air dried overnight and coverslipped with DPX. Bright-field microcopy was conducted using an Olympus BX-51 microscope. Fluorescent images were captured by laser scanning confocal microscopy (Meyer et al., 2008).

Two,3,5-triphenyltetrazolium chloride staining. The brains of animals recovered from MCAO were rapidly dissected and chilled in oxygenated artificial CSF (aCSF) and then sliced in $2 \mathrm{~mm}$ coronal sections. Slices were placed in 2\% 2,3,5-triphenyltetrazolium chloride (TTC) in PBS for $20 \mathrm{~min}$ at $30^{\circ} \mathrm{C}$, laser scanned directly, and analyzed by NIH ImageJ with viability values defined as the mean intensity. For neuroprotective effects of Indo A, the entire coronal section was used. All slices within experiments were scanned together and data were expressed as percentage of control staining. For Cdk5 CKO, striatal slices were used. Infarction volumes were quantified according to methods described by Yang et al. (1998).

Neurophysiology. Electrophysiological analyses were conducted in coronal slices (thickness, $270 \mathrm{~mm}$ ) from 1-2-month-old male rat brains as described earlier (Calabresi et al., 2002; Picconi et al., 2003; Costa et al., 2006). Briefly, slices were transferred to a recording chamber and submerged in a continuously flowing Kreb's buffer $\left(34^{\circ} \mathrm{C} ; 2.5-3 \mathrm{ml} / \mathrm{min}\right)$ bubbled with $95 \% \mathrm{O}_{2}$ and $5 \% \mathrm{CO}_{2}$. In rat slices, OGD was achieved by switching the Kreb's solution to an aCSF in which sucrose replaced glucose, gassed with $95 \% \mathrm{~N}_{2}$ and $5 \% \mathrm{CO}_{2}$. OGD solution was bath applied for $10 \mathrm{~min}$ during field potential (FP) recordings or for $3 \mathrm{~min}$ in $\mathrm{Mg}^{2+}$-free Kreb's solution during intracellular recordings. Electrophysiological recordings of FPs and single-unit activity were taken from slices under physiological and OGD conditions. An Axoclamp 2B amplifier (Molecular Devices) was connected in parallel to an oscilloscope (Hameg Instruments) to monitor the signal in "bridge" mode and to a PC for acquisition of intracellular and extracellular recordings using pClamp9 software (Molecular Devices). Intracellular re- 
cordings of striatal medium spiny neurons (MSNs) were obtained by using sharp microelectrodes backfilled with $2 \mathrm{M} \mathrm{KCl}$ (electrode resistance, 30-60 M $\Omega$ ). For extracellular recordings, electrodes were filled with $2 \mathrm{M} \mathrm{NaCl}$ (electrode resistance, 15-20 M $\Omega$ ). For recording striatal neuron electrophysiological responses, EPSPs or FPs were evoked every $10 \mathrm{~s}$ by a bipolar electrode connected to a biphasic stimulus isolation unit (SIU5, Grass Telefactor). The stimulating electrode was placed in cortical areas close to the recording electrode or in the white matter between the cortex and the striatum to activate corticostriatal fibers. The recording electrodes were placed within striatum. Stimulation intensity was increased until EPSP amplitude was stable and $\geq 20 \mathrm{mV}$. For inhibitor studies, slices were preincubated in Kreb's containing Cdk5 inhibitor (e.g., 10 mM Indo A for 30-120 min before the electrophysiological recordings). Data were quantified and expressed as a percentage of EPSP or FP with respect to the relative control amplitude values, the latter representing the mean of responses recorded during a stable period. Offline analysis was performed using Clampfit and GraphPad Prism. ANOVA and Bonferroni's post hoc test were used for statistical analysis. Values given are mean \pm SE. The significance level was established at $p<0.05$.

\section{Results}

P25 generation and dysregulation of

Cdk5 characterizes ischemic

stroke injury

To explore the role of aberrant Cdk5/p25 in ischemic stroke, we used a clinically relevant animal model in which focal ischemia is achieved by selective unilateral embolization of the MCA in aged rats. In this model, vascular reperfusion is established after $2 \mathrm{~h}$ of MCAO by tPA administration (Dinapoli et al., 2006). To confirm neuronal injury as a result of focal ischemia, striatal MSNs and pyramidal neurons of cortex were stained with FJB and GFAP (Fig. 1B). Degenerating neurons that experienced ischemic injury were detected with FJB, and the subsequent astrogliosis that accompanies ischemic injury (Clark et al., 1994; Stoll et al., 1998) was detected by increased GFAP staining $24 \mathrm{~h}$ after reperfusion (Larsson et al., 2001; Butler et al., 2002).

These neuropathological effects of ischemic stroke were accompanied by robust p25 generation in aged rat brain (Fig. 1C). Unilateral MCAO caused marked production of p 25 at both 6 and $48 \mathrm{~h}$ after thrombolysis in striatum. A similar pattern occurred in prefrontal cortex but with comparatively lower levels of p25 detected. Thus, p25 is generated in response to initial focal ischemic insult and during the delayed period of spreading damage that characterizes stroke pathophysiology.

B

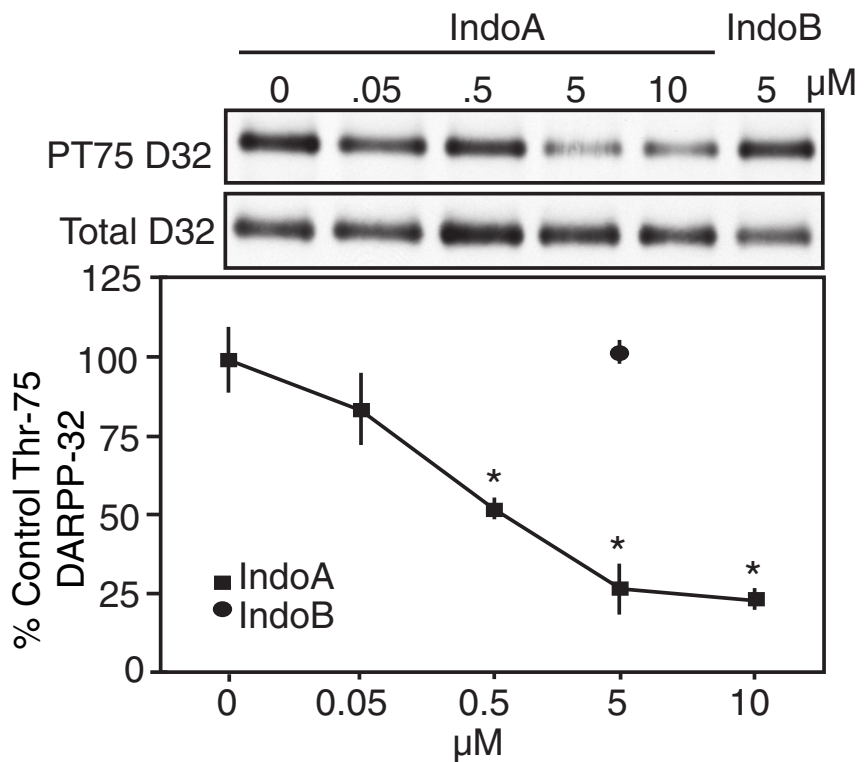

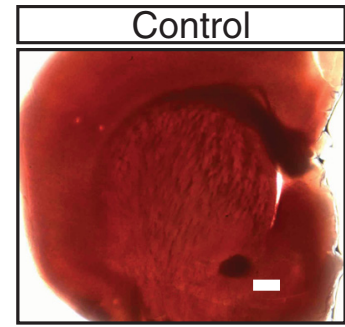

$30 \mathrm{~min}$

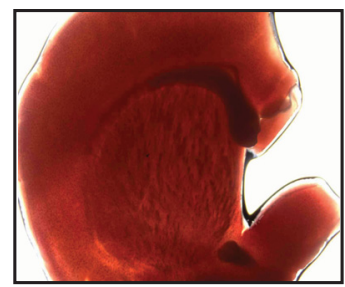

$60 \min$

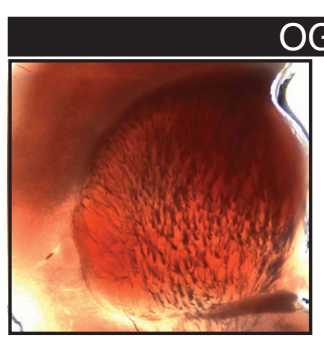

30 min

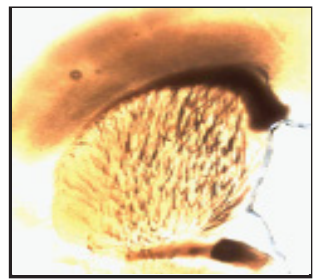

$60 \min$
GD

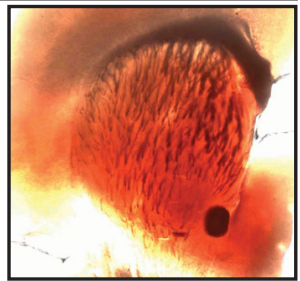

30 min, calpeptin

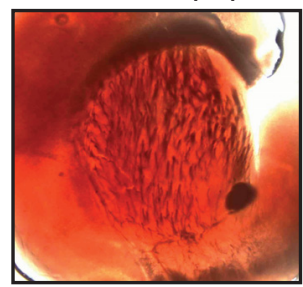

$30 \mathrm{~min}$, IndoA

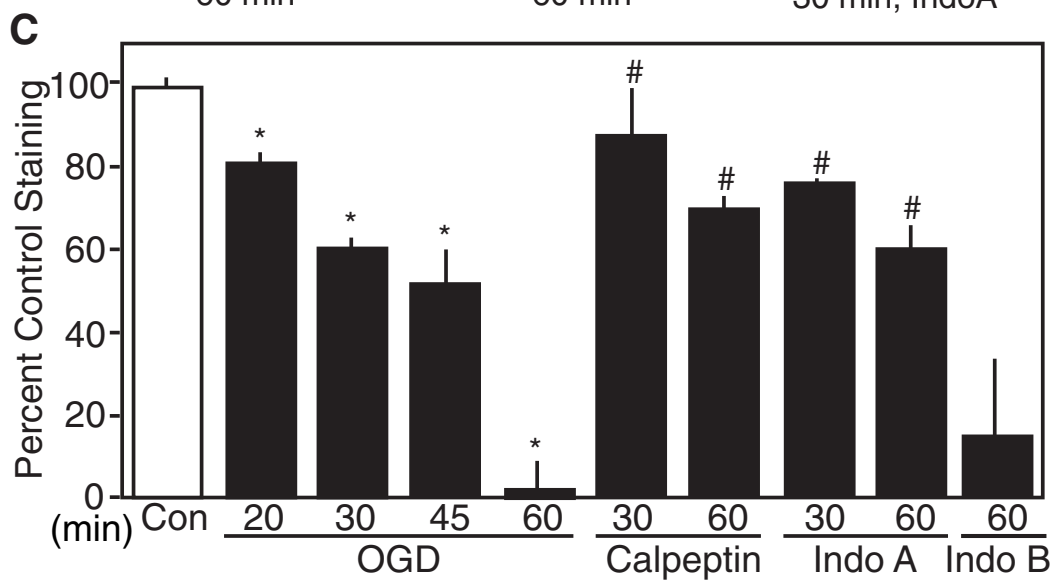

Figure 3. Inhibition of $C d k 5$ prevents neuronal cell death from ischemia in acute brain slices. $A$, Dose-responseinhibition of striatal $C d k 5$ by Indo A (1 h), as assessed by blotting phospho-Thr75 DARPP-32 (PT75 D32). B, Viability staining (TTC) of coronal slices after 30 or 60 min of OGD in the absence or presence of calpeptin or Indo A. C, Quantitation of the effects of calpeptin, Indo A, or indolinone B (Indo B) on viability. Data represent means $\pm \mathrm{SEM} ; n=4-6 ;{ }^{*} p<0.05$ versus control; $\# p<0.05$ versus same period of $0 \mathrm{GD}$ treatment alone; Student's $t$ test.

Given that generation of $\mathrm{p} 25$ is dependent upon calpain activity, we evaluated the levels of the cleaved spectrin isoform fodrin as a marker of calpain activity following ischemic insult. Embolic MCAO significantly enhanced fodrin cleavage in striatum and 

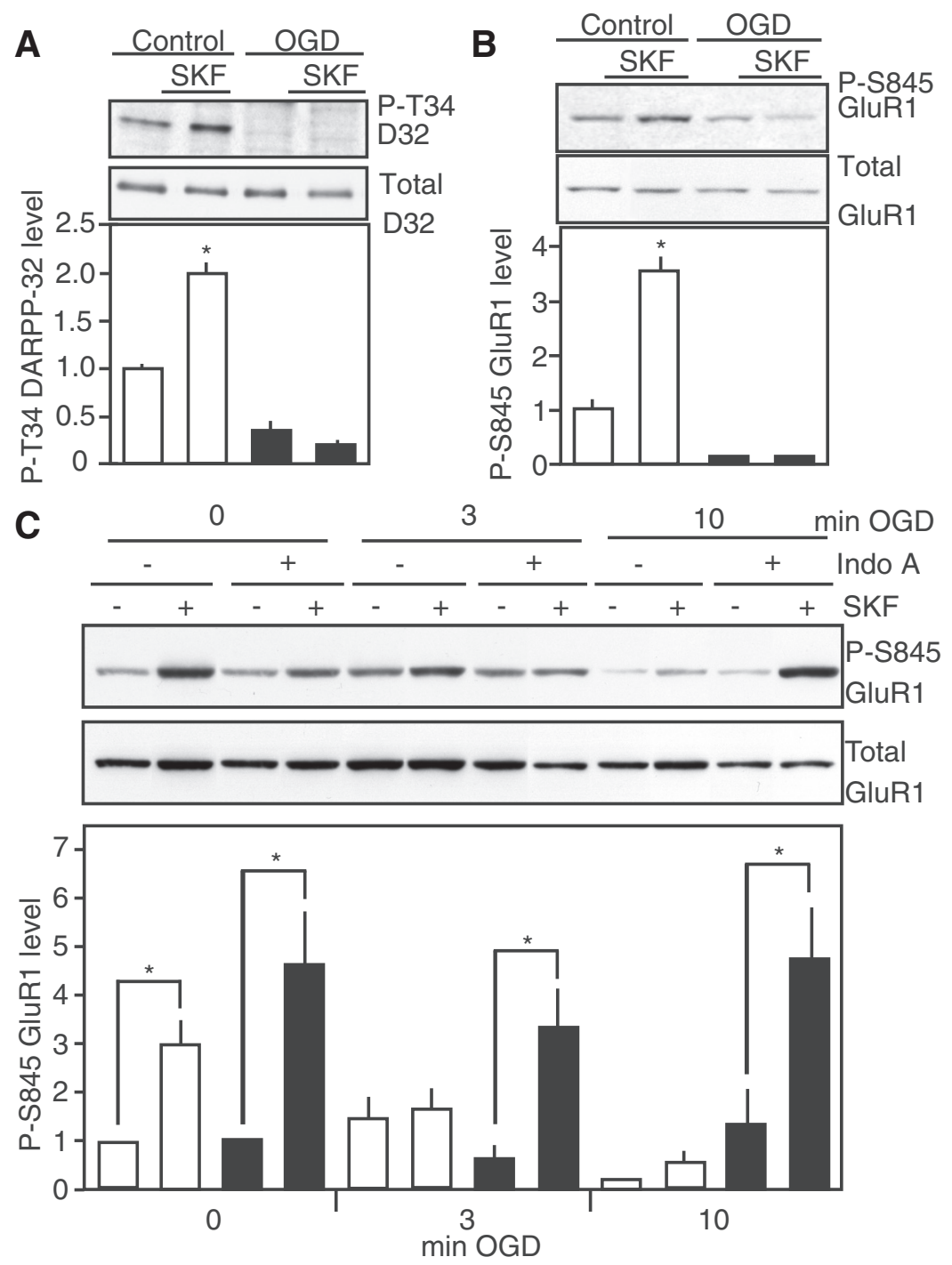

Figure 4. Ischemia-induced deficits in dopamine neurotransmission are $(d \mathrm{k} 5$ dependent. $A, B$, Effect of $20 \mathrm{~min} 0 \mathrm{GD}$ and $10 \mathrm{~min}$ reperfusion on $(\boldsymbol{A})$ phospho-Thr34 DARPP-32 and $(\boldsymbol{B})$ phospho-Ser845 GluR1 in striatal slices that were untreated or incubated with the D1 dopamine receptor agonist SKF81297 (SKF). C, Effects of 0, 3, or $10 \mathrm{~min}$ OGD and $10 \mathrm{~min}$ reperfusion on stimulation of phospho-Ser845 GluR1 by SKF81297 in the absence or presence of Indo A (1 h, $10 \mu \mathrm{M})$. Data represent means \pm SEM; $n=6$; ${ }^{*} p<$ 0.05 versus control; Student's $t$ test.

prefrontal cortex $6 \mathrm{~h}$ poststroke (Fig. 1D). The activation of calpain and the generation of p25 also corresponded to reduced phosphorylation of the physiological Cdk5/p35 substrate Thr75 DARPP-32 (Fig. 1E). Cdk5/p25 may represent a more soluble form of the kinase and DARPP-32, as a physiological substrate, is found in striatal cytoplasm. Nevertheless, these effects are consistent with those observed when transgenic p25 overexpression is induced in striatum (Meyer et al., 2008).

Inhibition of aberrant Cdk5 blocks ischemic neuronal death To study the mechanisms by which ischemia caused $\mathrm{p} 25$ production, the lysates from acutely prepared mouse striatal slices subjected to OGD were immunoblotted for p35 and p25 (Fig. 2A). In response to OGD, p25 accumulated in a time-dependent manner. To further assess p25 generation in response to ischemic conditions, primary cultures of rat striatal neurons were subjected to OGD for $20 \mathrm{~min}$. OGD induced p25 production throughout these neurons as well (Fig. 2B). P25 generation in OGD-treated striatal slices ( $20 \mathrm{~min}$ ) was blocked by removal of
$\mathrm{Ca}^{2+}$ from the buffer (Fig. 2C). Moreover, preincubation with the inhibitors calpeptin or calpain inhibitor 3 prevented p25 generation (Fig. 2D). As was observed with MCAO in vivo, the induction of $\mathrm{p} 25$ formation by ischemic conditions corresponded to increased cleavage of fodrin (Fig. 2E) and decreased phosho-Thr75 DARPP-32 (Fig. 2F). These data are consistent with the generation of p25 during ischemia as a result of $\mathrm{p} 35$ cleavage via the $\mathrm{Ca}^{2+}$-dependent activation of calpain.

To assess the deleterious effects of aberrantly active Cdk5/p25, the selective and potent Cdk5 inhibitor Indo A (Gillardon et al., 2005) was used. First, its ability to inhibit Cdk5 in striatal slices was assessed by ex vivo treatment with various concentrations $(1-10 \mu \mathrm{M}, 1 \mathrm{~h})$ of Indo $\mathrm{A}$ and blotting the lysates for the defined Cdk5 substrate site, phospho-Thr75 DARPP-32 (Bibb et al., 1999). Cdk5 inhibition dosedependently reduced phospho-Thr75, with $5 \mu \mathrm{M}$ Indo A causing a reduction to $26 \pm 8 \%$ of basal levels. Furthermore, the $\mathrm{IC}_{50}$ value of Indo A was defined as 0.29 $\mu \mathrm{M}$ (Fig. 3A). In contrast, the congener indolinone $\mathrm{B}$, which is limited in specificity to Cdk4 (Weishaupt et al., 2003), had no effect on Cdk5-dependent phosphorylation of DARPP-32. Thus, Cdk5 is effectively inhibited in intact striatal tissue by Indo A.

Using this pharmacological approach, the effect of OGD on neuronal viability was next assessed by TTC staining (Bederson et al., 1986; Fig. 3B,C). TTC staining was readily observed in coronal mouse brain slices oxygenated in buffer for $1 \mathrm{~h}$. OGD induced time-dependent neuronal death with TTC staining reduced to $60.8 \pm 2.1 \%$ and $0.6 \pm 7.9 \%$ of control levels by exposure to ischemic conditions for 30 and $60 \mathrm{~min}$, respectively. Incubation of slices with calpeptin or Indo A for $1 \mathrm{~h}$ before and during OGD significantly blocked neuronal death induced by ischemic conditions. Indeed, even after 60 min without oxygen and glucose, viability was maintained at $69.6 \pm 6.6 \%$ and $59.7 \pm 6.0 \%$ of control levels as a result of calpain or Cdk5 inhibition, respectively. Slices neuroprotected by calpeptin or Indo A stained $111.3 \pm 6.0$-fold or $95.5 \pm 9.6$-fold, respectively, more intensely than those subjected to $60 \mathrm{~min}$ OGD in the absence of either of these inhibitors. Indo B showed no such neuroprotective effect. These data indicate that inhibition of aberrant Cdk5 activity or calpain cleavage of p35 during ischemia is profoundly neuroprotective.

\section{Inhibition of aberrant Cdk5 protects dopamine} neurotransmission from ischemia

$\mathrm{MCAO}$, the most frequent form of ischemic stroke in humans, prevents oxygen and nutrient delivery to large areas of the brain, including the striatum. Within the striatum, dopamine neurotransmission is mediated by G-protein-coupled dopamine receptors, which modulate the adenylyl cyclase/cAMP/protein 
kinase A (PKA) cascade (Greengard et al., 1999). To characterize the deleterious effects of ischemia on striatal neuron function, brain slices were subjected to OGD and the efficacy of the D1 dopamine receptor agonist SKF81297 to invoke PKAdependent phosphorylation of Ser845 of the GluR1 subunit of the AMPA receptor or Thr34 of DARPP-32 was assessed in mouse striatal slices. In oxygenated slices, SKF81297 induced $2.0 \pm 0.1$-fold and $3.6 \pm 0.3$-fold increases in phospho-Ser845 GluR1 and phospho-Thr34 DARPP-32, respectively (Fig. 4A,B). However, in slices subjected to OGD for $20 \mathrm{~min}$, followed by 10 min of reperfusion in oxygenated buffer, this effect was completely absent and the basal level of phosphorylation of these sites was markedly attenuated.

Given the severity of deleterious effects induced by $20 \mathrm{~min}$ of ischemia, the effects of shorter periods of OGD, including 3 and $10 \mathrm{~min}$, on dopamine signaling were evaluated (Fig. 4C). While phosphorylation of Ser845 GluR1 was detectable after these shorter periods of OGD followed by reoxygenation, even $3 \mathrm{~min}$ of ischemia prevented SKF81297 from inducing any increase in phospho-Ser845 GluR1. Furthermore, $10 \mathrm{~min}$ of OGD substantially decreased the detectable basal level of phospho-Ser845 GluR1 (18 $\pm 6 \%$ of control). Interestingly, if the striatal tissue was first incubated with Indo A, D1 receptordependent signal transduction was maintained at normal levels even after $10 \mathrm{~min}$ of ischemia (4.7 \pm 1.2-fold increase in phospho-Ser845 in response to SKF81297). These results show the deleterious effects that even brief ischemia can have on striatal dopamine signaling. The data also indicate that aberrant Cdk5 activity contributes to loss of this signaling in response to ischemia. Moreover, these findings show that inhibition of aberrant $\mathrm{Cdk} 5$ activity protects dopamine neurotransmission from ischemic injury.

\section{Inhibition of aberrant Cdk5 protects striatal neurons from} excitotoxic effects and loss of FP associated with ischemia

To better understand the pathophysiological effects of shorter periods of ischemia, a neurophysiological approach was used. Sharp microelectrode intracellular recordings were obtained from striatal projecting spiny neurons identified according to their electrophysiological characteristics. Specifically, these neurons have small soma (diameter, 10-18 $\mu \mathrm{m}$ ) and an extensive dendritic tree, densely studded with spines. They have high resting membrane potential $(-80$ to $-90 \mathrm{mV})$, relatively low apparent input resistance $(\sim 40 \mathrm{M} \Omega)$, action potentials of short duration $(\sim 1.1 \mathrm{~ms})$, and high amplitude $(\sim 100 \mathrm{mV})$. These cells are silent at rest and exhibit membrane rectification and tonic firing activity during depolarizing current pulses (Calabresi et al., $1998)$. In these neurons, a brief period (2-3 min) of OGD induced loss of membrane potential (Fig. $5 A, B$ ) and a transient suppression of the EPSP followed by a long-term increase in the
EPSP amplitude compared with the preischemic period (139.7 \pm 10.3\%; Fig. 5C). This long-term increase of the glutamatergic transmission at corticostriatal synapses, called postischemic LTP (i-LTP), represents a pathological form of synaptic plasticity occurring after brain ischemia (Calabresi et al., 2002, 2003). The process of excitotoxicity likely initiates with membrane depolarization and $\mathrm{Ca}^{2+}$-dependent over-release of excitotoxic glutamate. i-LTP is the footprint of this process that, if continued out from 3 to $10 \mathrm{~min}$, results in death. Interestingly, pretreatment with Indo A completely blocked the induction of i-LTP at corticostriatal synapses (Fig. 5C,D) without affecting the amplitude or recovery time of membrane depolarization induced by the brief ischemic episode (Fig. 5B). Extracellular FP recordings were also obtained from corticostriatal slices. In control conditions, $10 \mathrm{~min}$ of OGD caused an irreversible loss of FP (Fig. $5 E, F$ ). Conversely, pretreatment of corticostriatal slices with Indo A significantly reduced the loss of FP induced by ischemia. These results indicate that inhibition of aberrant Cdk5 neuroprotects striatum from deleterious physiological effects of ischemia associated with excitotoxicity, loss of function, and neuronal cell death. 
A
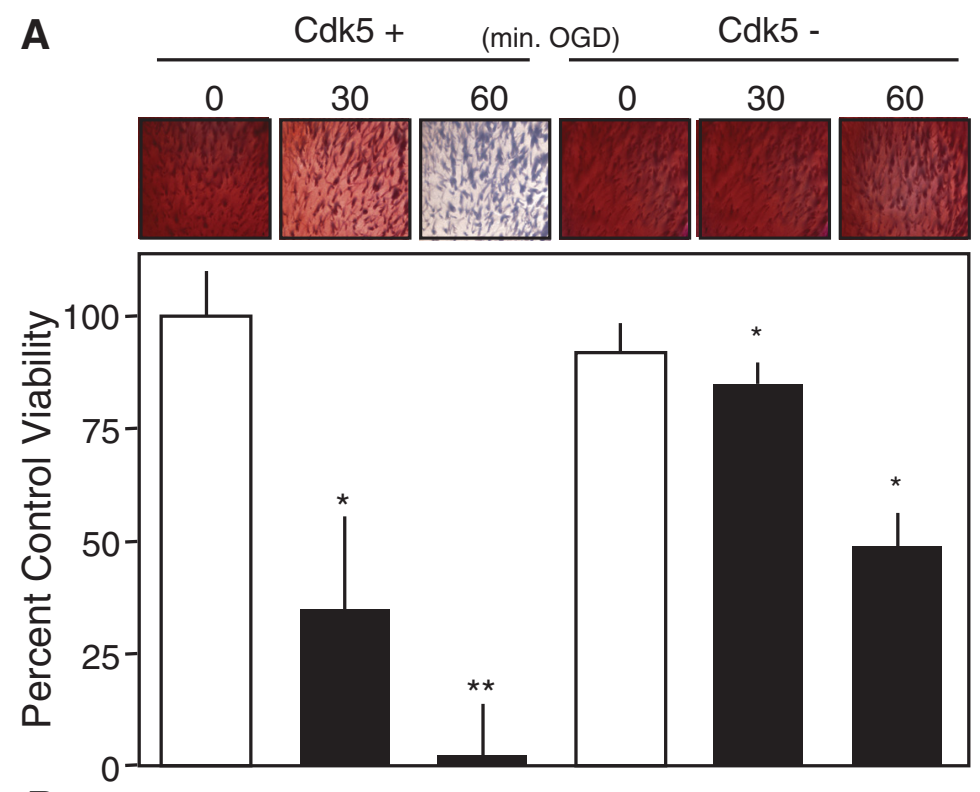

B
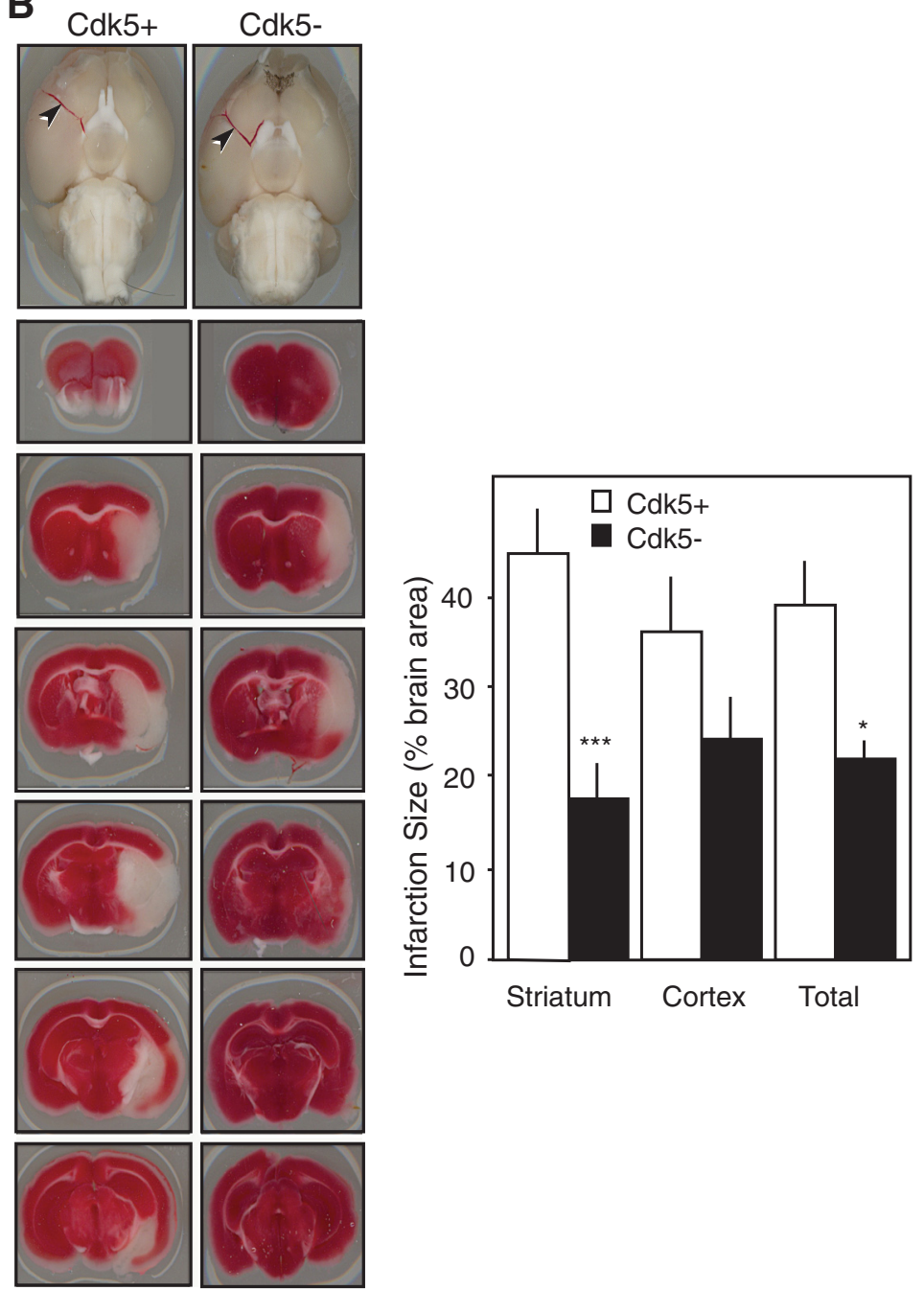

Figure 6. C $\mathrm{dk} 5$ CK0 is neuroprotective against ischemia and stroke. $A, \mathrm{TTC}$ staining of striatal slices from C $\mathrm{dk} 5+(\mathrm{WT})$ or Cdk5 (CKO) mice subjected to the indicated period of $O G D$ is shown with quantitation. Data represent means $\pm S E M ; n=6 ;{ }^{*} p<0.05$, ${ }^{* *} p<0.01$ versus $00 \mathrm{GD}$ control, and compared with same treatment for $\mathrm{Cdk} 5+; n=6 . B$, TTC-stained coronal brain sections from Cdk5 + or Cdk5 - mice after MCAO ( $2 \mathrm{~h}$ ), reperfusion, and $24 \mathrm{~h}$ survival. Top, Ventral view of brains from Cdk5 + and Cdk5 littermates showing a representative embolism of the MCA (arrows) verifying placement. Quantitation of infarct size is shown (right). Data represent means $\pm \mathrm{SEM} ; n=9 ;{ }^{* * *} p<0.001,{ }^{*} p<0.05 ;$ ANOVA with Bonferroni's post hoc, for each group.
Cdk5 CKO protects striatal neurons from ischemia-induced neuronal death and reduces stroke infarct volume

Previously, we reported the generation of Cdk5 CKO mice in which a $14 \mathrm{~d}$ regimen of 4-hydroxytamoxifen treatment results in pan-forebrain deletion of the $\mathrm{Cdk} 5$ gene in adult animals (Hawasli et al., 2007). Given that pharmacological inhibition of Cdk5 reduced the neurotoxic effects of OGD, we hypothesized that brain slices from CKO mice should be neuroprotected from ischemic insult. Therefore, we compared the effects of OGD on neuronal viability of striatal slices from WT versus CKO littermates (Fig. 6A). Cdk5 CKO was markedly neuroprotective. Viability in WT slices was reduced to $30 \pm 18 \%$ and $2 \pm 12 \%$ by 30 and $60 \mathrm{~min}$ of OGD, respectively. However Cdk5 CKO showed $80 \pm 4 \%$ and $49 \pm 7 \%$ viability in response to these treatments. These findings provide further evidence that aberrant Cdk5 mediates ischemic neuronal death.

To further assess the neuroprotective effects of Cdk5 CKO, MCAO was next conducted in WT versus Cdk5 CKO mice (Fig. 6B). Groups of littermate control and Cdk5 CKO mice underwent unilateral embolic MCAO and were maintained for $24 \mathrm{~h}$ after thrombolysis. Brains were dissected and infarct size determined. Cdk5 CKO resulted in a profound reduction of infarct volume with striatal infarct size reduced 2.6-fold from $44.7 \pm 5.4 \%$ of total brain area for controls to $17.1 \pm$ $4.4 \%$ for Cdk5 CKO mice. Furthermore, total infarct size was reduced 1.8 -fold from $38.8 \pm 4.9 \%$ to $21.8 \pm 4.9 \%$ of total brain area. Cortical infarct volume was not significantly reduced by CKO (36.1 \pm $6.2 \%$ for controls vs $23.8 \pm 5.3 \%$ for $\mathrm{CKO}, p=0.6$, Student's $t$ test), suggesting that aberrant Cdk5 may contribute more meaningfully to ischemic injury in response to MCAO in striatum where highest levels of p25 are produced. These results confirm that aberrant Cdk5 is a major cause of ischemic injury and that insults caused by ischemic stroke may be greatly reduced by its inhibition.

\section{Discussion}

We show that aberrant Cdk5 is a perpetrator of ischemic injury and stroke-induced neuronal death. Pharmacological or transgenic inhibition of aberrant Cdk5 was profoundly neuroprotective. Striatal dopamine neurotransmission and FPs were preserved, and excitotoxic potentiation of synaptic responses induced by ischemia was blocked by antagonism of aberrant 
Cdk5. The ability of aberrant Cdk5 inhibition to block striatal i-LTP is consistent with the dependence of i-LTP on the enhancement of intracellular $\mathrm{Ca}^{2+}$ triggered by depolarization, as intracellular BAPTA also completely prevents i-LTP in MSNs (Calabresi et al., 2002). Tissue remained viable even after $60 \mathrm{~min}$ of ischemia if aberrant Cdk5 activity was inhibited or knocked out, and striatal infarcts induced by MCAO were dramatically reduced by Cdk5 CKO.

Calpain plays an important role in the progression of ischemic damage (Wells and Bihovsky, 1998; Lipton, 1999), and calpain cleavage of p35 in response to hypoxia (Tamada et al., 2005) or stroke has been suggested to contribute to neuronal cell loss (Green and Cross, 1997; Nath et al., 2000; Rashidian et al., 2005). Here, we demonstrate enhanced calpain activity and corresponding aberrant Cdk5 activity is a principle cause of neuronal death in striatum, with p 25 marking ischemic injury in stroke. Aberrant Cdk5 may acutely perpetrate neuronal damage through a shift in specificity with reduced phosphorylation of physiological substrates and hyperphosphorylation of aberrant or neurotoxic substrates. Indo A prevents mitochondrial fission in necrotic and apoptotic paradigms of neuronal cell death (Weishaupt et al., 2003). Although the pathways responsible remain to be elucidated, such mechanisms may overlap with those mediating chronic neurodegeneration (Patrick et al., 1999).

Even brief ischemia-induced dysregulation of striatal dopamine neurotransmission, an important component of the limbic circuitry that controls emotion, is prevented by inhibition of aberrant Cdk5. Thus, inhibition of aberrant Cdk5 may be neuroprotective with regard to some of the nonmotor neuropsychiatric and behavioral effects of stroke, including poststroke depression (Loubinoux et al., 2012). The neuroprotective effect of Cdk5 $\mathrm{CKO}$ in MCAO did not extend to the cortex, perhaps due to the limited collateral vascularization of the striatum versus the cortex and less cortical p25 generation. NMDA receptor antagonists exhibit selective protection of cortex (Nath et al., 2000; Weishaupt et al., 2003; Rashidian et al., 2005), but striatal-specific neuroprotection is rare or unique.

Cdk5 functions in neurogenesis (Lagace et al., 2008), synaptic remodeling (Cheung $U$ et al., 2006), and cognition (Hawasli et al., 2007), all of which may be important for eventual stroke recovery. Blocking this normal physiological activity over a prolonged treatment period would likely produce unwanted side effects and hinder long-term rehabilitation. Also, since it is impossible to predict ischemic events in patients, it would be more applicable to examine the effects of Cdk5 inhibition poststroke. Therefore, acute inhibition of Cdk5 during the period immediately following stroke should be examined as a potential treatment strategy. Combining this approach with revascularization by tPA, which is currently the only United States Food and Drug Administration-approved pharmacological treatment for ischemia, may help improve patient recovery from ischemic injury. Unfortunately, such experiments await the availability of systemic Cdk5 inhibitors. While our findings cannot be directly inferred to have clinical relevance, they highlight the need for identifying molecular mechanisms of ischemic injury, which may then serve as the basis for the development of more effective clinical treatments.

\section{References}

Alkayed NJ, Murphy SJ, Traystman RJ, Hurn PD, Miller VM (2000) Neuroprotective effects of female gonadal steroids in reproductively senescent female rats. Stroke 31:161-168. CrossRef Medline

Alvira D, Tajes M, Verdaguer E, Acuña-Castroviejo D, Folch J, Camins A,
Pallas M (2006) Inhibition of the cdk5/p25 fragment formation may explain the antiapoptotic effects of melatonin in an experimental model of Parkinson's disease. J Pineal Res 40:251-258. CrossRef Medline

Bederson JB, Pitts LH, Germano SM, Nishimura MC, Davis RL, Bartkowski HM (1986) Evaluation of 2,3,5-triphenyltetrazolium chloride as a stain for detection and quantification of experimental cerebral infarction in rats. Stroke 17:1304-1308. CrossRef Medline

Bibb JA, Snyder GL, Nishi A, Yan Z, Meijer L, Fienberg AA, Tsai LH, Kwon YT, Girault JA, Czernik AJ, Huganir RL, Hemmings HC Jr, Nairn AC, Greengard P (1999) Phosphorylation of DARPP-32 by Cdk5 modulates dopamine signalling in neurons. Nature 402:669-671. CrossRef Medline

Bibb JA, Yan Z, Svenningsson P, Snyder GL, Pieribone VA, Horiuchi A, Nairn AC, Messer A, Greengard P (2000) Severe deficiencies in dopamine signaling in presymptomatic Huntington's disease mice. Proc Natl Acad Sci U S A 97:6809-6814. CrossRef Medline

Butler TL, Kassed CA, Sanberg PR, Willing AE, Pennypacker KR (2002) Neurodegeneration in the rat hippocampus and striatum after middle cerebral artery occlusion. Brain Res 929:252-260. CrossRef Medline

Calabresi P, Centonze D, Pisani A, Sancesario G, Gubellini P, Marfia GA, Bernardi G (1998) Striatal spiny neurons and cholinergic interneurons express differential ionotropic glutamatergic responses and vulnerability: implications for ischemia and Huntington's disease. Ann Neurol 43:586597. CrossRef Medline

Calabresi P, Saulle E, Centonze D, Pisani A, Marfia GA, Bernardi G (2002) Post-ischaemic long-term synaptic potentiation in the striatum: a putative mechanism for cell type-specific vulnerability. Brain 125:844-860. CrossRef Medline

Calabresi P, Centonze D, Pisani A, Cupini L, Bernardi G (2003) Synaptic plasticity in the ischaemic brain. Lancet Neurol 2:622-629. CrossRef Medline

Centonze D, Marfia GA, Pisani A, Picconi B, Giacomini P, Bernardi G, Calabresi P (2001) Ionic mechanisms underlying differential vulnerability to ischemia in striatal neurons. Prog Neurobiol 63:687-696. CrossRef Medline

Cheung U, Atwood HL, Zucker RS (2006) Presynaptic effectors contributing to cAMP-induced synaptic potentiation in Drosophila. J Neurobiol 66:273-280. CrossRef Medline

Cheung ZH, Fu AK, Ip NY (2006) Synaptic roles of Cdk5: implications in higher cognitive functions and neurodegenerative diseases. Neuron 50: 13-18. CrossRef Medline

Clark RK, Lee EV, White RF, Jonak ZL, Feuerstein GZ, Barone FC (1994) Reperfusion following focal stroke hastens inflammation and resolution of ischemic injured tissue. Brain Res Bull 35:387-392. CrossRef Medline

Costa C, Martella G, Picconi B, Prosperetti C, Pisani A, Di Filippo M, Pisani F, Bernardi G, Calabresi P (2006) Multiple mechanisms underlying the neuroprotective effects of antiepileptic drugs against in vitro ischemia. Stroke 37:1319-1326. CrossRef Medline

Dinapoli VA, Rosen CL, Nagamine T, Crocco T (2006) Selective MCA occlusion: a precise embolic stroke model. J Neurosci Methods 154:233238. CrossRef Medline

Gillardon F, Schrattenholz A, Sommer B (2005) Investigating the neuroprotective mechanism of action of a CDK5 inhibitor by phosphoproteome analysis. J Cell Biochem 95:817-826. CrossRef Medline

Green AR, Cross AJ (1997) Techniques for examining neuroprotective drugs in vivo. Int Rev Neurobiol 40:47-68. Medline

Greengard P, Allen PB, Nairn AC (1999) Beyond the dopamine receptor: the DARPP-32/protein phosphatase-1 cascade. Neuron 23:435-447. CrossRef Medline

Hagemann G, Redecker C, Neumann-Haefelin T, Freund HJ, Witte OW (1998) Increased long-term potentiation in the surround of experimentally induced focal cortical infarction. Ann Neurol 44:255-258. CrossRef Medline

Hawasli AH, Benavides DR, Nguyen C, Kansy JW, Hayashi K, Chambon P, Greengard P, Powell CM, Cooper DC, Bibb JA (2007) Cyclindependent kinase 5 governs learning and synaptic plasticity via control of NMDAR degradation. Nat Neurosci 10:880-886. CrossRef Medline

Lagace DC, Benavides DR, Kansy JW, Mapelli M, Greengard P, Bibb JA, Eisch AJ (2008) Cdk5 is essential for adult hippocampal neurogenesis. Proc Natl Acad Sci U S A 105:18567-18571. CrossRef Medline

Larsen GA, Skjellegrind HK, Berg-Johnsen J, Moe MC, Vinje ML (2006) Depolarization of mitochondria in isolated CA1 neurons during hypoxia, 
glucose deprivation and glutamate excitotoxicity. Brain Res 1077:153160. CrossRef Medline

Larsson E, Lindvall O, Kokaia Z (2001) Stereological assessment of vulnerability of immunocytochemically identified striatal and hippocampal neurons after global cerebral ischemia in rats. Brain Res 913:117-132. CrossRef Medline

Lipton P (1999) Ischemic cell death in brain neurons. Physiol Rev 79:14311568. Medline

Lo EH, Dalkara T, Moskowitz MA (2003) Mechanisms, challenges and opportunities in stroke. Nat Rev Neurosci 4:399-415. CrossRef Medline

Loubinoux I, Kronenberg G, Endres M, Schumann-Bard P, Freret T, Filipkowski RK, Kaczmarek L, Popa-Wagner A (2012) Post-stroke depression: mechanisms, translation and therapy. J Cell Mol Med 16:1961-1969. CrossRef Medline

Meyer DA, Richer E, Benkovic SA, Hayashi K, Kansy JW, Hale CF, Moy LY, Kim Y, O'Callaghan JP, Tsai LH, Greengard P, Nairn AC, Cowan CW, Miller DB, Antich P, Bibb JA (2008) Striatal dysregulation of Cdk5 alters locomotor responses to cocaine, motor learning, and dendritic morphology. Proc Natl Acad Sci U S A 105:18561-18566. CrossRef Medline

Monaco EA 3rd (2004) Recent evidence regarding a role for Cdk5 dysregulation in Alzheimer's disease. Curr Alzheimer Res 1:33-38. CrossRef Medline

Nath R, Davis M, Probert AW, Kupina NC, Ren X, Schielke GP, Wang KK (2000) Processing of cdk5 activator p35 to its truncated form (p25) by calpain in acutely injured neuronal cells. Biochem Biophys Res Commun 274:16-21. CrossRef Medline

Nishi A, Snyder GL, Greengard P (1997) Bidirectional regulation of DARPP-32 phosphorylation by dopamine. J Neurosci 17:8147-8155. Medline

Patrick GN, Zukerberg L, Nikolic M, de la Monte S, Dikkes P, Tsai LH (1999) Conversion of $\mathrm{p} 35$ to $\mathrm{p} 25$ deregulates $\mathrm{Cdk} 5$ activity and promotes neurodegeneration. Nature 402:615-622. CrossRef Medline

Picconi B, Centonze D, Håkansson K, Bernardi G, Greengard P, Fisone G, Cenci MA, Calabresi P (2003) Loss of bidirectional striatal synaptic plasticity in L-DOPA-induced dyskinesia. Nat Neurosci 6:501-506. Medline

Rashidian J, Iyirhiaro G, Aleyasin H, Rios M, Vincent I, Callaghan S, Bland RJ, Slack RS, During MJ, Park DS (2005) Multiple cyclin-dependent kinases signals are critical mediators of ischemia/hypoxic neuronal death in vitro and in vivo. Proc Natl Acad Sci U S A 102:14080-14085. CrossRef Medline

Sahin B, Kansy JW, Nairn AC, Spychala J, Ealick SE, Fienberg AA, Greene RW, Bibb JA (2004) Molecular characterization of recombinant mouse adenosine kinase and evaluation as a target for protein phosphorylation. Eur J Biochem 271:3547-3555. CrossRef Medline

Sahin B, Galdi S, Hendrick J, Greene RW, Snyder GL, Bibb JA (2007) Evaluation of neuronal phosphoproteins as effectors of caffeine and mediators of striatal adenosine A2A receptor signaling. Brain Res 1129:1-14. CrossRef Medline

Sahin B, Hawasli AH, Greene RW, Molkentin JD, Bibb JA (2008) Negative regulation of cyclin-dependent kinase 5 targets by protein kinase C. Eur J Pharmacol 581:270-275. CrossRef Medline

Smith PD, Mount MP, Shree R, Callaghan S, Slack RS, Anisman H, Vincent I, Wang X, Mao Z, Park DS (2006) Calpain-regulated p35/cdk5 plays a central role in dopaminergic neuron death through modulation of the transcription factor myocyte enhancer factor 2. J Neurosci 26:440-447. CrossRef Medline

Stoll G, Jander S, Schroeter M (1998) Inflammation and glial responses in ischemic brain lesions. Prog Neurobiol 56:149-171. CrossRef Medline

Tamada Y, Nakajima E, Nakajima T, Shearer TR, Azuma M (2005) Proteolysis of neuronal cytoskeletal proteins by calpain contributes to rat retinal cell death induced by hypoxia. Brain Res 1050:148-155. CrossRef Medline

Weber P, Metzger D, Chambon P (2001) Temporally controlled targeted somatic mutagenesis in the mouse brain. Eur J Neurosci 14:1777-1783. CrossRef Medline

Weishaupt JH, Kussmaul L, Grötsch P, Heckel A, Rohde G, Romig H, Bähr M, Gillardon F (2003) Inhibition of CDK5 is protective in necrotic and apoptotic paradigms of neuronal cell death and prevents mitochondrial dysfunction. Mol Cell Neurosci 24:489-502. CrossRef Medline

Wells GJ, Bihovsky R (1998) Calpain inhibitors as potential treatment for stroke and other neurodegenerative diseases: recent trends and developments. Expert Opin Ther Pat 8:1707-1727. CrossRef

Yang Y, Shuaib A, Li Q (1998) Quantification of infarct size on focal cerebral ischemia model of rats using a simple and economical method. J Neurosci Methods 84:9-16. CrossRef Medline

Zhang RL, Chopp M, Zhang ZG, Jiang Q, Ewing JR (1997) A rat model of focal embolic cerebral ischemia. Brain Res 766:83-92. CrossRef Medline 